\title{
Factors influencing pregnancy induced hypertension among women treated in Khulna Medical College Hospital
}

\author{
N Nazneen ${ }^{1}$, MS Laskar², PP Barua ${ }^{3}$, SD Haque ${ }^{4}$
}

\begin{abstract}
Pregnancy induced hypertension (PIH) complicates approximately $6 \%$ of pregnancies globally and it is the most important cause of maternal and neonatal morbidity and mortality. The purpose of the cross sectional descriptive type of study was to assess the sociodemographic/economic characteristics of women with $\mathrm{PIH}$ in a selected tertiary care hospital. Respondents were selected by purposive sampling technique and data were collected by face to face interview using a semi-structured type of questionnaire. In this study, the number purposively selected respondents was 113 who came for treatment in gynecology and obstetrics related inpatient and outpatient departments of the hospital. It was found that the age of mothers was directly and significantly $(p<0.01)$ associated with $\mathrm{PIH}$. The development of PIH was higher in the educated mothers than illiterate or less educated mothers. The relationship between PIH and educational status was significant $(p<0.01)$. The association between the proportion of mothers with $\mathrm{PIH}$ and family history of hypertension was also statistically significant $(p<0.01)$. Awareness regarding the associated risk factors for $\mathrm{PIH}$ shall be helpful in reducing the PIH related morbidity and mortality.
\end{abstract}

Key words: Hypertension, pregnancy induced, factors.

\section{Introduction}

Worldwide about 50000 mothers die per year due to pregnancy induced hypertension (PIH). Hypertension in pregnancy complicates around $5-10 \%$ of all pregnancies. ${ }^{1} \mathrm{PIH}$ includes a group of hypertension disorders developed due to the gravid state after 20 weeks of pregnancy. It includes gestational hypertension with blood pressure $>140 / 90$ $\mathrm{mmHg}$ without proteinuria, pre-eclampsia which is gestational hypertension with proteinuria and eclampsia defined as preeclampsia with convulsions. ${ }^{2}$ The incidence of pre-eclampsia in nulliparous population ranges from 3 to $10 \%$ worldwide. ${ }^{3}$ Incidence of eclampsia in the developed countries is about 1 in 2000 deliveries as compared to developing countries where it varies from 1 in 100 to 1 in $1700.4,5-7$ The national incidence of $\mathrm{PIH}$ is $15 \%$ in Bangladesh, while it is four times higher in primipara women than in multipara. ${ }^{8}$

Thirteen percent of the maternal deaths are in the women with $\mathrm{PIH}$ and eclampsia, the most terrible form that accounts for major cause of death among pregnant women. ${ }^{9}$ The high incidence observed has pointed towards poverty, lack of education and unawareness regarding health care in this part of the world. PIH is more common in primiparous, women of younger age, high

\footnotetext{
1. N Nazneen MBBS, MPH, Assistant Professor of Community Medicine, Gazi Medical College, Khulna email: nidhi_nazia@yahoo.com

2. MS Laskar MD, MPH, PhD, Professor of Community Medicine, Gazi Medical College, Khulna

3. PP Barua MBBS, MPhil, Associate Professor of Community Medicine, Rangamati Medical College, Rangamati

4. SD Haque MBBS, Lecturer, Department of Community Medicine, Gazi Medical College, Khulna
} 
maternal age, multiple pregnancies, obese women and hydatidiform mole; previous history of PIH is also an important risk factor for the development of $\mathrm{PIH}$. In addition, the genetic factor is also involved. Patients who have a family history of $\mathrm{PIH}$, especially in mother or sister are at higher risk. ${ }^{10}$ The age of mother is also important; with increasing age, the risk of $\mathrm{PIH}$ increases. ${ }^{11}$

The aim of the present cross sectional descriptive type of study was to determine the association of the socio-demographic/ economic profile of women with $\mathrm{PIH}$ in a selected tertiary care hospital

\section{Materials and Method}

It was a cross-sectional type of descriptive study. The study was carried out at gynae and obstetric related inpatient and outpatient departments of a tertiary hospital namely Khulna Medical College Hospital. All the pregnant mothers who developed hypertension in pregnancy attended in Khulna Medical College Hospital was the study population. All the subjects were informed in details about the nature and purpose of the study and included in the study only when they had given their written consent. Purposive type of sampling technique was followed. Data were collected four to five days in a week by face-to-face interview. The research instrument was pretested questionnaire containing structured and nonstructural questions. After collection the data were edited, verified for its consistency. Then data analysis were done using SPSS version 19 for windows. Statistical signifi- cance was measured according to the objectives of the study. Statistical analysis was done using appropriate tests of significance e.g. for comparison of continuous data using Student's $t$-test, for the categorical variables Chi-square test and for the difference in proportion of variables $z$ - test. Statistical significance was considered significant when $p<0.05$.

\section{Results}

Table 1 shows different characteristics of the hypertensive pregnant mother. The mean (SD) age of the mothers was 24.5 (4.8) years when the mean (SD) age of mothers at marriage was 16.7 (2.2) years. The literacy rate was as high as $82.4 \%$. Most of the women were from lower middle class socio-economic status. The percentage of service holder women, multipara, with family history of hypertension, previous history of pre-eclampsia, previous history of abortion and previous history of hypertension was 37.2, 77.0, 55.7, 31.9, 24.8 and $48.7 \%$, respectively.

Table 2 shows the cross tabulation on $\mathrm{PIH}$ and some socio-demogrphic/economic characteristics of the pregnant mothers. It was found that age of the mothers was and significantly $(p<0.01)$ associated with PIH. The development of PIH was higher in the educated mothers than illiterate or less educated mothers. The relationship between $\mathrm{PIH}$ and educational status was significant $(p<0.01)$. The association between the proportion of mothers with $\mathrm{PIH}$ and family history of hypertension was also statistically significant $(p<0.01)$.

Table 1. Characteristics of the hypertensive pregnant mothers, $n=113$

\begin{tabular}{lrr}
\hline Characteristics & Number & $\%$ \\
\hline Age, years, mean \pm SD & $24.5 \pm 4.8$ & \\
Age at marriage, years, mean \pm SD & $16.7 \pm 2.2$ & 82.4 \\
Literacy & 93 & \\
Socio-economic status & & 54.0 \\
$\quad$ Lower middle class & 61 & 37.2 \\
Service holder & 42 & 77.0 \\
Parity status of mothers (multipara) & 87 & 55.7 \\
Family history of hypertension & 63 & 31.9 \\
History of previous pre-eclampsia & 36 & 24.8 \\
History of previous abortion & 28 & 48.7 \\
History of previous hypertension & 55 & \\
\hline
\end{tabular}


Table 2. Cross tabulation on pregnancy induced hypertension and some socio-demogrphic/ economic characteristics of the pregnant mothers, $n=113$

\begin{tabular}{|c|c|c|c|c|}
\hline & \multicolumn{2}{|c|}{ Pregnancy induced hypertension } & \multirow{2}{*}{$\begin{array}{l}\text { Total } \\
\mathrm{n}(\%)\end{array}$} & \multirow[t]{2}{*}{$p$ value } \\
\hline & $\begin{array}{c}\text { Gestational } \\
\text { hypertension } \\
n(\%)\end{array}$ & $\begin{array}{c}\text { Preeclampsia } \\
\mathrm{n}(\%)\end{array}$ & & \\
\hline \multicolumn{5}{|l|}{ Age } \\
\hline 12 to 24 years & $38(33.7)$ & 15(13.2) & $53(46.9)$ & \multirow{3}{*}{$p<0.01$} \\
\hline 24 years and above & $38(33.7)$ & $22(19.4)$ & $60(53.1)$ & \\
\hline & & & 113(100.0) & \\
\hline \multicolumn{5}{|l|}{ Occupation } \\
\hline Day laborer & $6(5.3)$ & $5(4.4)$ & $11(9.7)$ & \multirow{4}{*}{$p>0.05$} \\
\hline House wife & $46(40.7)$ & $14(12.4)$ & $60(53.1)$ & \\
\hline Service holder & $24(21.3)$ & 18(15.9) & 42(37.2) & \\
\hline & & & 113(100.0) & \\
\hline \multicolumn{5}{|c|}{ Educational status } \\
\hline Illiterate & 10(8.8) & 10(8.8) & $20(17.7)$ & \multirow{5}{*}{$p<0.01$} \\
\hline Primary & $39(34.5)$ & $12(10.6)$ & $51(45.1)$ & \\
\hline Secondary & $19(16.8)$ & $9(8.0)$ & $28(24.8)$ & \\
\hline A bove & $8(7.1)$ & $6(5.3)$ & $14(12.4)$ & \\
\hline & & & 113(100.0) & \\
\hline \multicolumn{5}{|c|}{ Socio-economic status } \\
\hline Lower middle class & $20(17.7)$ & $13(11.5)$ & $33(29.2)$ & \multirow{3}{*}{$p>0.05$} \\
\hline Upper middle class & $42(37.2)$ & $19(16.8)$ & $61(54.0)$ & \\
\hline Upper class & $14(12.3)$ & $5(4.43)$ & $19(16.8)$ & \\
\hline & & & $113(100.0)$ & \\
\hline \multicolumn{5}{|c|}{ Family history of hypertension } \\
\hline Yes & $34(30.0)$ & $29(25.6)$ & $63(55.6)$ & \multirow{3}{*}{$p<0.01$} \\
\hline No & $42(37.3)$ & $8(7.1)$ & $50(44.4)$ & \\
\hline & & & $113(100.0)$ & \\
\hline
\end{tabular}

Rounding was done for making the total as 100.

\section{Discussion}

A cross sectional descriptive study was designed and conducted with the objective of exploring the socio-demographic/ economic characteristics of women with $\mathrm{PIH}$ of the mothers attending gynecology and obstetrics related inpatient and outpatient departments in Khulna Medical College Hospital.

The study showed that most of the respondents, $46.0 \%$, developed moderate hypertension, $30.9 \%$ developed severe hypertension and $23.0 \%$ mild hypertension. It was found that age of the mothers significantly associated with $\mathrm{PIH}$. Sahu et al reported the maternal age to be significantly higher in cases as compared to controls. ${ }^{12}$ Our study showed that elder pregnant women might have contributed to a greater frequency of $\mathrm{PIH}$. The US nationwide data proposed that the danger of $\mathrm{PIH}$ increases by $30 \%$ for each additional year of age past $34 .{ }^{13}$ Yadav et al concluded that the threat of $\mathrm{PIH}$ was greater when the age of pregnant women was less than 25 years, and this observation was in conformity with ours. ${ }^{14}$ Increased age of women was reported to be an important risk factor due to increased villous reaction leading to pre-eclampsia in a woman greater than 30 years and this has been conclusively found in various studies. ${ }^{15,16}$

The literacy rate among the mothers was $82.3 \%$, higher than that of other parts of the country. The current literacy rate in Bangladesh is about $58.8 \% .{ }^{8}$ It may be due to that 
the data of the present study were collected from a section of married couples at tertiary level hospital and most of the mothers lived within and around the city. The development of PIH was higher in the educated mothers than illiterate or less educated mothers. The relationship between $\mathrm{PIH}$ and educational status was directly significant. Higher incidence of $\mathrm{PIH}$ among literate women in our study was in conformity with a report in which similar higher incidence was observed in literate women. ${ }^{17,18} \mathrm{~A}$ report states that women with college education had 19\% greater chances of having $\mathrm{PIH}$ which was due to the reason that these women were more aware about their health problems as compared to illiterate women. ${ }^{18}$ Women with low income group usually have tendency to ignore ailments/ symptoms associated with pregnancy and cannot afford to utilize the available health care services at nearby clinics/ hospitals. Therefore, their visit to the hospital is not as frequent as those of literate women with higher income group.

The association between the proportion of mothers with PIH and family history of hypertension was also statistically significant. A study has also supported by similar findings that women whose mothers had a history of hypertension, preeclampsia or eclampsia were at increased risk of severe preeclampsia. The risk of preeclampsia was greater when the woman had a sister with a history of hypertension, preeclampsia, or eclampsia. ${ }^{19}$ The risk of preeclampsia was also higher for women who had both a mother and sister with a history of hypertension. ${ }^{19}$

So, identified the risk factors for developing hypertension and socio-demographic status of the mothers with PIH which have a role in primary prevention of $\mathrm{PIH}$ creating awareness about $\mathrm{PIH}$ and its complication during antenatal visits and reinforcing the health care providers the importance of screening and early detection of $\mathrm{PIH}$ and timely intervention will be helpful in reducing this problem.

\section{Conclusion}

This study provided information to explore the socio-demographic/economic characteristics of women with PIH. From this study, it can be concluded that there is a definite relationship between socio-demographic/ economic factors and $\mathrm{PIH}$. Therefore, there is further need to elaborate the study using larger population including more study subjects and socio-demographic parameters to establish better statistical correlation.

\section{References}

1. Navneet M, et al. Hypertension in pregnancy: the endocrine and metabolic aspect. Indian J Endocrinol Metab 2011; 15(Suppl 4):S380-2.

2. Sharma A, Mahendra P, Bisht S. Management of pregnancy induced hypertension. IJRAP 2010;1(2):390-8.

3. Sibai BM, Cunningham FG. Prevention of preeclampsia and eclampsia. In: Lindheimer MD, Roberts JM, Cunningham FG. Editors. Chesley's hypertensive disorders of pregnancy. 3rd edition, Elsevier, New York, 2009.

4. Douglas KA, Redman CWG. Eclampsia in the United Kingdom. Br Med J 1994; 309:1395-400.

5. World Health Organization. International collaborative study of hypertensive disorders of pregnancy. Geographic variation in the incidence of hypertension in pregnancy. Am J Obstet Gynecol 1988; 158(1):80-3.

6. Crowther CA. Eclampsia at Harare maternity hospital. An epidemiological study. S Afr Med 1985;68(13):927-9.

7. Bergstrom S, Povey G, Songane F, Ching C. Seasonal incidence of eclampsia and its relationship to metereological data in Mozambique. J Perinat Med 1992;20(2):153-8.

8. National Health Bulletin, Bangladesh. 2014.

9. Rashid Khabir Haider, Textbook of Preventive and Social Medicine, 4th Edition, Bangladesh. 2010.

10. Sayeda Nurzahan Bhuiyan. Clinical guide to obstetrics and gynaecology. 8th edition.

11. Zhang J. Partner change, birth interval and risk of pre-eclampsia: a paradoxical triangle. Paediatr Perinat Epidemiol 2007;21(Suppl 1):31-5.

12. Sahu S, Abraham R, Vedavalli R, Daniel M. Study of lipid profile, lipid peroxidation and vitamin $E$ in pregnancy induced hypertension. Indian J Physiol Pharmacol 2009;53(4):365-69.

13. Saftlas AF, Olson DR, Franks Al, Atrash HK, Pokras R. Epidemiology of preeclampsia and eclampsia in the 
United States, 1979-1986. Am J Obstet Gynecol 1990;163(2):460-5.

14. Yadav S, Yadav R, Saxena U; Hypertensive disorders of pregnancy and perinatal outcome. J Obstet Gynecol India 1997; 17:322-30.

15. Duckitt K, Harrington D. Risk factors for pre-eclampsia at antenatal booking: systematic review of controlled studies. BMJ 2005;330:565.

16. Leppälahti Suvi, Gissler Mika, Mentula Maarit, Heikinheimo Oskari. Is teenage pregnancy an obstetric risk in a welfare society? A population-based study in Finland, from 2006 to 2011. BMJ 2013;3(8):e003225.
17. Saxena S, Srivastava PC, Thimmaraju $\mathrm{KV}$, Mallick AK, Dalmia K, Das B. Socio-demographic profile of pregnancy induced hypertension in a tertiary care centre. Sch J App Med Sci 2014; 2(6D):3081-6.

18. American Society of Nephrology. News release, Nov. 8, 2008. Available from http://www.wrongdiagnosis.com/hd/news/ 621138. pregnant-rural-womenmore-at-ri sk.htm

19. Bezerra PC, Leão MD, Queroz JW, et al. Family history of hypertension as an important risk factor for the development of severe preeclampsia. Acta Obstet Gynecol Scand 2010;89(5):612-7.

\section{Suggestion for citation of the above:}

Nazneen N, Laskar MS, Barua PP, Haque SD. Factors influencing pregnancy induced hypertension among women treated in Khulna Medical College Hospital. Mediscope 2016;3(2):31-5. 